\title{
MODALIDADES DISCURSIVAS EN LA FICCIÓN POSMODERNA ESPAÑOLA
}

Desde principios de siglo tanto formalistas rusos como estructuralistas han venido dedicando parte de sus esfuerzos al estudio del discurso narrativo. Los formalistas rusos distinguen entre "fable" y "sjuzet"1, mientras que para los estructuralistas la materia narrativa consiste de dos partes: el discurso y la historia $^{2}$. El discurso literario ha sido motivo de estudio desde los clásicos griegos hasta nuestros días. Ya en su Poética (p. 17), Aristóteles entiende la narrativa — diégesis- como uno de los dos modos de imitación —mimesis—; el otro modo correspon-

${ }^{1}$ La "fable", fábula o historia, se basa en el desarrollo cronológico de los hechos. Éstos están sujetos a una relación de causa y efecto, mientras que en el "sjuzet" o "plot" los segmentos narrativos aparecen en el texto sin arreglo cronológico alguno. Dentro de esta categoría incluye Shklovsky todas aquellas técnicas narrativas que detienen el curso de la narración mediante el uso de descripciones, digresiones, etc. (SELDEN, pp. 12-13).

2 R. Scholes define el discurso de acuerdo con el modo "in which the present contact between speaker and listener is emphasized. Discourse is rhetorical and related to oral persuasion" (p. 111), mientras que la historia es "the mode of written description of events... Story is referential and related to written documentation. Discourse is «now»; story is «then»" (Semiotics, p. 111). Scholes aclara que la información dada sobre acciones, menciones del tiempo, etc., forma parte de la historia; mientras que las reflexiones, evaluaciones, o la lengua que sugiere la presencia de una voz narrativa dirigiéndose al lector con fines persuasivos se identifica con el discurso. Para Chatman, que define la historia y el discurso en términos muy similares a Scholes, la historia se concentra en el contenido de las acciones, personajes y partes del ambiente; y el discurso en el medio de comunicación del contenido (Chatman, p. 20). G. GENETte, por otra parte, define la historia como "the totality of the narrated events", la narrativa como "the discourse, oral or written, that narrates them”, y añade una nueva categoría: narración, que entiende como "the real or fictive act that produces that discourse -in other words, the very fact of recounting..." (Narrative discourse, p. 3). 
dería a la representación de la realidad por actores frente a una audiencia. En el tercer libro de La República (p. 150), Platón indica que "lexis" - forma de decir algo, y opuesta a "logos", que designa el contenido de lo dicho- se divide en imitación o mimesis y simple narrativa o diégesis. La diferencia entre una y otra clasificación se reduce a mera terminología, ya que, en esencia, los dos filósofos están de acuerdo en que la representación dramática de la realidad es más imitativa o mimética que el género narrativo ${ }^{3}$. Las continuas definiciones de mimesis y diégesis son una muestra del interés que sigue suscitando el tema en medios de la crítica y teoría literarias. Según A. Jefferson, "diegesis consists in the representation of objects, events, and actions, whereas mimesis consists in the representation of actual utterances" (p. 112) ${ }^{4}$.

Aunque no hay consenso en la crítica a la hora de etiquetar el movimiento de la posmodernidad, una de las características que sí ha ganado aprobación unánime es la de la preeminencia del discurso diegético sobre el discurso mimético, imperante este último en la novela del realismo social. En el discurso de la posmodernidad no se pretende como objetivo prioritario la transustanciación de la palabra en realidad porque la lengua no busca su reproducción objetiva; al contrario, el nuevo discurso narrativo complica sus propias formas de representación y la unidad orgánica que tipificaba a la novela realista se ve ahora en jaque, desmembrada en múltiples partes que desafían la noción de coherencia y sentido. A diferencia de la novela realista, en la que el escritor buscaba el dominio y control de la lengua para que ésta tradujera con fidelidad la realidad exterior, en la posmodernidad, señala Foucault, "language wells up in an enigmatic multiplicity that must be mastered", el hombre ya no habla, sino la palabra, y finalmente termina por perderse en un universo verbal (The order, p. 305). La crítica ha resaltado la existencia en la posmodernidad de una pluralidad de discursos que rechaza el concepto humanista liberal de la subjetividad que descansa en la idea de una concien-

${ }^{3}$ Me sirvo de la explicación que Genette facilita en su obra Figures of literary discourse. Consúltese para mayor información el capítulo "Frontieres of narrative" (pp. 127-144).

${ }^{4}$ Para GenetTe, "diegesis is pure narrative (without dialogue), in contrast to the mimesis of dramatic representation and to everything that creeps into narrative along with dialogue, thereby making narrative impure - that is, mixed" (Narrative discourse, p. 18). 
cia unificada, racional y autodeterminante (Giroux, p. 23) Asimismo, en el texto posmoderno se interrumpe el desarrollo cronológico de la anécdota y la relación entre la fábula y el sjuzet entra en conflicto. La posmodernidad acentúa el principio de discontinuidad y, según Foucault, las diferentes manifestaciones discursivas pueden formar ocasionalmente una unidad o excluirse unas a otras (The archaeology, p. 229) ${ }^{6}$. Es muy común, además, encontrar que el tejido discursivo esté formado por retazos de textos de otras obras -intertextualidad-, o que los diferentes planos narrativos se superpongan o imbriquen complicando la tarea identificadora.

Estas, y otras muchas características que se asignan a la posmodernidad, van a la par con la sensibilidad consumista y la cultura e ideología del capitalismo. El fenómeno de la discontinuidad también se produce en nuestra sociedad, y se manifiesta en los continuos cambios de moda, la yuxtaposición de noticias - terror, información trivial, deportes, política, romances, etc.- en la primera página de un periódico o en la emisión de noticias; y todo esto "does more to assault hierarchically ordered thinking than the most uncompromising example of anti-object art" (Graff, p. 97). Es evidente que el interés depositado en la forma y en las múltiples técnicas formales y experimentales, como la parodia, el pastiche, el collage y otros juegos lingüísticos o textuales, suponen un ataque y una resistencia a la "oppressive homogeneity that is enforced by the dominant institutions in modern society" (Deer, p. 354). Otro de los aspectos intrínsecamente vinculado a la posmodernidad es el de la ironía. Para Hassan la ironía afirma un universo pluralista (p. 449), mientras que para $\mathrm{H}$. White la ironía implica una actitud hacia el conocimiento manifiestamente crítica de todas las formas de identificación metafórica, y cuestiona todo el sistema tropológico (Tropics, p. 73) ${ }^{7}$.

${ }^{5}$ El modernismo buscaba la representación de la subjetividad, se ponía énfasis en el fluir de conciencia, y "the lived experience of time and memory, and the effects of the unconscious on conscious experience" (Mepham, p. 141). Estos aspectos de la modernidad irán perdiendo gradualmente terreno en la posmodernidad.

${ }^{6}$ I. HASSAN reduce la posmodernidad a once rasgos dominantes, algunos de ellos son la fragmentación, el rechazo de la mimesis, la mezcla de estilos o hibridación, el carácter lúdico del texto, etcétera.

${ }^{7} \mathrm{H}$. White parte de los arquetipos narrativos de N. Frye y propone en su obra Tropics of discourse cuatro tropos correspondientes cada uno de ellos a un tipo de argumento: el tropo de la metáfora encuentra expresión 
La novela española, a partir de la publicación de Tiempo de silencio (1961), se integra de lleno en la posmodernidad y comienza a dar prioridad a los juegos formales y experimentales, a la fragmentación del discurso, a las innovaciones lingüísticas, a la dislocación de la sintaxis, y así nace, según G. Sobejano, una lengua renovada que rompe las formas de la novela realista (p. 605). En este trabajo es mi intención estudiar algunas novelas posmodernas españolas en las que destaca la experimentación discursiva y la disidencia con respecto al canon de la novela realista.

La publicación de Tiempo de silencio de Luis M. Santos marca un cambio de rumbo en la novela española y crea una nueva teoría estética en la que el discurso ya no va a estar supeditado al contexto que recrea, sirviéndole de vehículo o medio de comunicación, sino que ambos van a ir caminando a la par. En una buena parte de las novelas publicadas con posterioridad a Tiempo de silencio, el discurso diegético cobrará una atención prioritaria desbancando en importancia al discurso mimético, al diálogo y a la representación fiel del referente. No se puede negar que Tiempo de silencio expone con gran fidelidad la estructura social de la España de los 40, incluso el habla de algunos personajes los vincula de inmediato a una determinada clase o grupo social. El Cartucho, por ejemplo, utiliza una lengua con abundante jerga callejera tipo caló; Pedro, que pertenece a la clase media, se expresa con un lenguaje más culto o científico, y el policía que lo interroga escribe un informe siguiendo los registros de la lengua oficial. Pero paralelamente a este lenguaje mimético y unidireccional que apunta a la realidad misma y busca encapsularla y ser imagen de ella, existen otras modalidades discursivas en las que, sin ignorar el referente, el discurso cobra verdadera carta de naturaleza. Desde un primer momento llama la atención en esta novela el carácter esquizofrénico de su discurso ${ }^{8}$. Según Jung, el ego ocupa el centro de nuestra atención, de nuestra conciencia y de nuestro deseo; pero si el ego se divide, como sucede en los casos de esquizofrenia, ciertas partes de la psique se refieren a un fragmento del ego y otras al otro fragmento. En estos casos, obviamente, el inconsciente se opone a la conciencia, y aquél se convierte en

en el argumento del romance, la metonimia en el trágico, la sinécdoque en la comedia y la ironía en los satíricos.

8 J. Schraibman observa esta cualidad del lenguaje en Tiempo de silencio, pero no la elabora. 
una fuerza desordenada y caótica (Jung, pp. 11-12, 353). A nivel discursivo existe en esta novela un deliberado desajuste entre el significante y el significado, entre el fondo y la forma, que guarda cierta relación con la naturaleza irónica de ciertas partes del texto que comentaré más adelante. En varios segmentos narrativos se puede apreciar este desajuste cuando utiliza una lengua culta, técnica o científica para reflejar una realidad trivial y huera con la que guarda una clara disonancia. Así, las chabolas a las que se dirigen Pedro y el Muecas son descritas como "los soberbios alcázares de la miseria" (p. 50$)^{9}$, las dos primeras secciones de la novela, donde se relata el ínfimo nivel de la investigación española y se realiza una crítica generalizada de España y los españoles, siguen un discurso técnico y culto, y la sección dedicada al prostíbulo de doña Luisa, en donde caen Matías y Pedro, emplea un discurso vinculado a la iglesia o la casuística religiosa que contrasta con el ambiente frívolo que describe. El burdel, por citar un ejemplo, se describe con la siguiente perífrasis: "lugares sagrados, templos de celebración de los nocturnales ritos órficos" (p. 99). Obviamente, al utilizar un discurso con un estilo y un lenguaje cultos se acentúa y agranda el margen que lo separa de la realidad representada. Pero, fundamentalmente, la falta de armonía entre las ideas y emociones del esquizofrénico, que se proyecta en el discurso, se refleja asimismo en el conflicto existente entre Pedro y la sociedad, y entre el Pedro como persona y el genuino investigador. Pedro habla como científico e investigador, pero la realidad de sus acciones contradice su discurso. Por otra parte, Pedro es incapaz de mantener una comunicación lógica y coherente con el policía que lo interroga sobre el aborto de Florita; todo lo que dice tiene que ver con sus investigaciones sobre el cáncer, que el policía no entiende, y termina confesándose homicida de un crimen que no cometió. Las acciones de Pedro son impelidas por los instintos, y a continuación su intelecto lo empuja a la reflexión y al análisis introspectivo. Esta dicotomía del ser forma parte de la concepción estructural de la novela, y a nivel textual se concretiza en el momento en que se yuxtapone la descripción del cuadro de Goya sobre el gran buco —el instinto- con la charla de Ortega y Gasset - el intelecto ${ }^{10}$.

${ }^{9}$ Utilizo la siguiente ed.: Luis Martín Santos, Tiempo de silencio, Seix Barral, Barcelona, 1981.

10 Consúltese el estudio de Betty J. Craige sobre las implicaciones narrativas de este episodio. Señala B. Craige cómo el narrador identifica la 
Aparte del discurso esquizofrénico existen otros recursos narrativos, como la ironía y la parodia, que complican la representación mimética de la realidad. La ironía, en la que como es sabido operan dos significados, uno explícito y otro simulado, funciona en Tiempo de silencio con una fuerte intención sarcástica y satírica. Así, el narrador explica el itinerario que ha seguido la cepa cancerígena de ratones provenientes de Illinois hasta llegar al Muecas "en una caja de huevos vacía" (p. 11), lo cual la invalida para que Pedro realice sus investigaciones sobre el cáncer inguinal ${ }^{11}$. A diferencia de la ironía, la parodia necesita del concurso de una realidad o texto exterior que es importado al nuevo texto con fines desconstructivos. Según Kristeva, el fin que persigue la parodia es introducir "a signification opposed to that of the other's word" (p. 73). Quizá el ejemplo más claro de parodia venga dado por la exposición que realiza Ortega y Gasset sobre su teoría del perspectivismo con ayuda de una manzana. El filósofo aparece caricaturizado y su presentación queda reducida a una breve alocución plagada de incisos con los que se ridiculiza su teoría. Luis M. Santos crea en esta novela un nuevo discurso narrativo, repleto de neologismos, en el que las numerosas reflexiones se apartan del hilo conductor de la anécdota. Esto, unido a los cambios de lugar, tiempo y perspectiva complica la tarea interpretativa del lector y lo invita a participar activamente en el proceso de creación. Todo ello forma parte de una nueva estética en la que se transfiere nuestra percepción de lo social a lo artístico y que los formalistas rusos, en concreto V. Shklovsky, llaman "ostranenie" o extrañamiento. Según F. Jameson, uno de los efectos del extrañamiento consiste en dar prioridad a una nueva percepción del mundo que permita un nuevo concepto de la historia literaria basado no en términos de progresión lineal sino en términos de discontinuidades y rupturas con el

pezuña izquierda del buco con el instinto y la fuerza de la naturaleza, y la derecha con el intelecto. La misma analogía se establece entre el buco y Ortega y Gasset.

${ }^{11}$ M. UGarte estudia la ironía desde otro punto de vista. Menciona tres clases de ironía en la novela: situacional, dramática y verbal. La primera se produciría cuando Pedro ayuda al Muecas y termina en la cárcel por no rellenar el certificado de defunción; la segunda tiene lugar con la muerte de Dorita a manos del Cartucho; y la tercera, que guarda cierta relación con el discurso esquizofrénico que he comentado, surge del uso de hipérboles para describir lo mundano (pp. 340-350). 
pasado (Jameson, p. 52). Uno de los objetivos que se persigue con el extrañamiento y la retardación, según los formalistas rusos, es incrementar y prolongar la duración del goce estético $^{12}$. En la novela posmoderna española, desde Luis M. Santos en adelante, se intensifica la atención en la lengua y en los procesos de construcción narrativa. Comparten estos escritores, además, una visión bastante caótica y pesimista del mundo que se manifiesta en cómo algunos de los protagonistas de estas novelas indagan desesperadamente en su pasado tormentoso para explicar su presente conflictivo; recordemos a los protagonistas de Juan y Luis Goytisolo, los de Benet, etcétera.

Benet fue uno de los primeros escritores en formar escuela con su amigo Luis M. Santos, pero mientras que a éste le interesaba reflejar la dialéctica de la sociedad con sus contradicciones, a Benet le preocupa recrear la confusión que experimentan sus personajes cuando intentan recuperar el pasado. En Volverás a Región (1964), el doctor Daniel Sebastián y Marré Gamallo se reúnen para hablar de su pasado, pero el diálogo se transforma en un monólogo interno. El discurso se basa en la oralidad, se hablan pero no se escuchan, y a las distintas perspectivas contradictorias con las que miran al pasado se une la voz del narrador sin propósitos reconciliadores. Los personajes de Benet viven amarrados al recuerdo, víctimas de un pasado que los ata a rememorarlo y vivirlo obsesivamente, condenados, como Sísifo, a reanudar repetidamente en su discurso una tarea expiatoria para experimentar frustradamente, cual Tántalo, la dificultad e imposibilidad que entraña asir las experiencias de su pasado. Marré se lamenta de los límites de su memoria, incapaz de hacerle recordar tiempos pretéritos: "La memoria nunca me trae recuerdos; es más bien todo lo contrario, la violencia contable del olvido" (p. 115) ${ }^{13}$. La memoria sólo puede recordar partes del pasado, momentos aislados de una totalidad inabarcable ${ }^{14}$. Al lado de este discurso ensimismado, que

12 Para un estudio de estos conceptos consúltese el trabajo de SHkLovsky "Art as technique". Para Shklovsky: "The technique of art is to make objects «unfamiliar» to make forms difficult, to increase the difficulty and length of perception, because the process of perception is an aesthetic end in itself and must be prolonged. Art is a way of experiencing the artfulness of an object; the object is not important" (p. 12).

13 Cito por la ed. de Destino, Barcelona, 1981.

14 R. Pope señala que no todos los enigmas son resueltos ni para los personajes ni para los lectores, y que la mente es el lugar de encuentro de diversos instantes de tiempo que miran al pasado (p. 116). 
arranca y gira en torno a la memoria, Benet echa mano del discurso de la historia, y contextualiza la acción narrativa en la guerra civil española. Republicanos y nacionalistas se enfrentan en Región, pero dentro de los republicanos existen dos bandos opuestos, el de los jóvenes republicanos idealistas representados por Marré y el de los viejos republicanos representados por el doctor Sebastián. La lucha entre nacionalistas y republicanos traduce un enfrentamiento entre pasión y razón y un control por el miedo y el deseo ${ }^{15}$. Historiar la guerra civil española se ha convertido en uno de los semas narrativos de la novela española de posguerra, y para Benet la historia alimenta el discurso literario como objeto de ficción. H. White indica al respecto que hay que diferenciar entre:

A historical discourse that narrates and a discourse that narrativizes, between a discourse that openly adopts a perspective that looks out on the world and reports it and a discourse that feigns to make the world speak itself and speak itself as a story (The content, p. 2).

Otro de los discursos que cultiva Benet con asiduidad es el de la topografía y orografía. Benet comienza Volverás a Región describiendo con la precisión científica del geólogo el paisaje de Región, un paisaje que a veces cumple funciones metafóricas y otras, como indica R. Spires, es transformado "en el mítico jardín de Nemi” donde la fertilidad es una amenaza tras la que se esconde la idea de sacrificio ritual a manos del Numa (Spires, pp. 237-241).

El término que normalmente utiliza la crítica para calificar el discurso de Benet es el de enigmático. Aunque Benet acostumbra iniciar párrafos o capítulos con expresiones tales como "es seguro", "es cierto", "se trataba de", etc., a medida que se adentra en la pormenorización de los hechos la narración se llena de incertidumbre ante los innumerables cabos que quedan sueltos. Por ejemplo, el narrador no explica el destino de un grupo de fugitivos que desaparecieron en enero de 1939 cuando dice "En realidad no hay una sola noticia exacta con referencia a aquellos fugitivos" (p. 90), poco después añade "se

${ }^{15}$ Me sirvo del penetrante estudio que realiza LABANY I sobre el significado de la guerra civil en esta novela (pp. 112, 129). N. ORRINGER, en cambio, desecha la importancia de la historia en Región: "The Civil War in Región does not deserve consideration as anything but a mock epic" (p. 44). 
dice que..." (p. 90) y a continuación "Tampoco hay acuerdo acerca de la identidad y el número de los fugitivos" (loc. cit.). Estos ejemplos ilustran a nivel microcósmico la falta de confianza que inspira en el lector este narrador. La novela invita a su recomposición, pero todo esfuerzo por encontrar una explicación a lo que ocurre fracasa porque el texto no propone una reproducción fiel de la realidad; antes bien, ésta se difiere indefinidamente porque incluso a los mismos personajes se les escapa de la mano. Aunque el uso de los discursos histórico y geográfico, además del diálogo entre los personajes, sugiera la idea de un discurso mimético, la realidad es que se trata de un disfraz o simulacro bajo el que se oculta un discurso diegético sujeto a progresivos desplazamientos y marcado por el signo de la indeterminación que hace imposible la búsqueda de un centro de significación. Derrida comenta al respecto que "this movement of play, permitted by the lack or absence of a center or origin, is the movement of supplementarity" (Writing, p. 289), y nunca llegamos a un origen de las cosas porque todas ellas nos remiten a uno y otro punto en una secuencia ilimitada ${ }^{16}$. La lectura de Volverás a Región se ve complicada también por la dislocación espacio-temporal, creando la ilusión ficticia de un desplazamiento en el tiempo ${ }^{17}$.

Reivindicación del Conde don Julián (1970), de Juan Goytisolo, comparte con Volverás a Región algunos de los rasgos que acabo de mencionar: fragmentación de la anécdota, subversión de la lógica espacio-temporal, localización de la acción en un espacio cerrado de la mente, y rememoración obsesiva de unos hechos que no llegan a corporificarse. Pero a diferencia de la novela anterior, en Reivindicación se produce un ataque a la lengua y sintaxis sin precedentes en la literatura española. Señala Foucault que la Edad Media tildaba de loco a todo aquél cuyo discurso se separaba del discurso del resto

${ }^{16}$ En Of grammatology, Derrida señala que "the supplement supplements. It adds only to replace. It intervenes or insinuates itself in-the-placeof" y añade que el suplemento es un instante adjunto, subalterno, que reemplaza a algo y no produce alivio (p. 145).

${ }^{17}$ Según D. Herzberger, la escritura de Benet "is a persistent maze of complex obstructions, delays, ambiguous interpolations and, confusions" ("The Emergence...", p. 9). María E. Bravo destaca cómo Benet congela una escena, como si se tratase de una toma fotográfica, y ésta despertará "una serie de reacciones que ensambladas darán distintas impresiones y todas aproximadas, metafóricas, del mundo interior del narrador o del personaje" (p. 253). 
de la comunidad, pero algunas veces el paso del tiempo ha demostrado que las palabras de este disidente revelaban una verdad oculta o poderes extraños que el resto de la sociedad racional no podía percibir ("The discourse on language", p. 217). El discurso de J. Goytisolo es igualmente el de un disidente que se rebela y rehúsa aceptar una determinada tradición histórico-cultural. Según Hutcheon, la posmodernidad trata de mostrar la complicidad entre discurso y poder al poner énfasis en la enunciación: "The act of saying is an inherently political act... Discourse is both an instrument and an effect of power" (Discourse, p. 112). Observa Hutcheon, citando a Foucault, que el discurso es el punto de confluencia, poder y conocimiento, y su significado y forma cambiará de acuerdo con el hablante, con su posición de poder y con el contexto en que se encuentre el hablante.

Para Foucault "it is the moving substrate of force relations which, by virtue of their inequality, constantly engender states of power" (The history, pp. 93, 100). En Reivindicación, el narrador-protagonista ha optado por el exilio como renuncia a unos valores que no acepta y que se propone reemplazar por otros de origen árabe. Dirige uno de los ataques contra una de las más genuinas manifestaciones del espíritu nacional: la lengua. Goytisolo puebla su texto de neologismos, argentinismos, dialectalismos, anglicismos, etc., pero, sobre todo, de préstamos de vocablos árabes a los que el narrador les da la fuerza creadora de lo que designan. Precisamente, una de las estrategias imaginadas por el narrador para destruir España consiste en eliminar las aportaciones árabes que tuvieron una gran influencia en el desarrollo y progreso de España en su tiempo: "privarás de álgebra a las escuelas y a las contabilidades de cifras... secarás acequias, motivarás infecciones y epidemias al desbaratar el arduo, laborioso sistema de alcantarillas..." (p. 199) ${ }^{18}$. Otra de las formas de proceder contra la lengua es quebrantando las reglas de puntuación y la sintaxis oficial, "abrupta ruptura con la oficial sintaxis" (p. 152). La experimentación a que se somete el discurso de Reivindicación desafía continuamente la tarea interpretativa del lector. En el texto se funde lo real con lo imaginario, el pasado con el presente y futuro, la ficción con la historia (G. Pérez, p. 155) y el desarrollo de la anécdota se produce mediante el uso de la técnica de li-

18 Utilizo la ed. de Seix Barral, Barcelona, 1985. 
bre asociación, saltando de idea en idea, de pensamiento en pensamiento (K. Schwartz, p. 965). El acontecer de la novela se mueve con frenética rapidez; la omisión de una puntuación académica provoca una especie de delirio o vértigo del discurso que entona con el espíritu agitado y eufórico de una imaginación iconoclasta. El verbo es omitido en muchas oraciones, y al romperse la ubicación temporal del relato el discurso se mueve con gran celeridad; las palabras parecen fluir como un torrente imparable imitando la tropelía invasora de las hordas árabes. El tono narrativo es muy similar al del poema de Espronceda "El canto del cosaco", en donde la invasión de la débil y afeminada Europa va acompañada de un acto de agresión sexual, como en Reivindicación ${ }^{19}$.

Pero quizá el aspecto que más sorprenda en esta novela sea el uso exacerbado de la intertextualidad. Según Thomas M. Greene la intertextualidad describe el itinerario o genealogía de una imagen compleja, texto, etc., y la define como la presencia estructural dentro de una obra de elementos de obras previas (Greene, p. 16) ${ }^{20}$. Desde un punto de vista estructural la intertextualidad fragmenta la unidad orgánica del texto. El texto interpolado, o subtexto, es un elemento exógeno que mantiene una relación dialógica con el nuevo texto. Los formalistas rusos, y en concreto Bakhtin, estudiaron cómo la literatura se escribe a partir de un diálogo con otras obras o autores precedentes. Goytisolo incorpora textos literarios, de la prensa o enciclopedias para parodiar, subvertir o satirizar los mitos y toda una tradición cultural que ha modelado el espíritu y la idiosincrasia españoles ${ }^{21}$. La parodia y la ironía son también los recursos que utilizará el narrador de Recuento para desconstruir los discursos de las ideologías dominantes en la España de posguerra.

Recuento (1973), de Luis Goytisolo, junto con las otras tres novelas que completan la tetralogía Antagonía, tienen una

${ }^{19}$ De la bibliografía que he consultado sobre la novela no he encontrado ningún estudio que comente la obvia relación entre el poema de Espronceda y la novela de J. Goytisolo.

${ }^{20}$ Para KrISTEVA "tout texte se construit comme mosaique de citations, tout texte est absorption et transformation d'un autre texte" (Séméotikè, p. 146). Laurent Jenny señala que "l'intertextualité désigne... le travail de transformation et d'assimilation de plusieurs textes opéré par un texte centreur qui guarde le leadership du sens" (p. 262).

${ }^{21}$ Consúltese el libro de M. UGarTe para un estudio pormenorizado de la parodia e intertextualidad en Reivindicación. 
gran importancia desde el punto de vista de la experimentación discursiva. Mientras que Recuento exhibe una rica variedad de discursos político-sociales, el resto de la tetralogía es un exponente modelo del discurso metaficticio. El discurso de los primeros capítulos de Recuento es transparente, denotativo y mimético, un discurso propio de la novela del realismo social. Pero a partir del capítulo 6 el discurso se convierte en objeto y objetivo de la escritura. Es un discurso lleno de largas perífrasis, circunloquios, y de un barroquismo que nos recuerda a Luis M. Santos y J. Goytisolo. La descripción de Barcelona (p. 213)22 por medio de largas concatenaciones de adjetivos y sustantivos, a veces beligerantes, en los que se percibe el vértigo del discurso nos recuerda la pintura que Luis M. Santos nos da de la prostituta con la que se acuesta Matías (Tiempo de..., p. 104). Y lo mismo que en Tiempo de silencio, donde se imbrica un plano narrativo sobre otro - escena del gran buco y el filósofo-, en Recuento el discurso marxista de Escala es desacreditado cuando el narrador lo silencia superponiendo a él el discurso de la historia de Barcelona. Otros discursos discernibles y parodiados en Recuento son el de la falangista Montserrat, tía de Raúl, el del cura de la prisión que sermonea en la cárcel donde se halla preso Raúl, y los idiolectos del charnego y del trabajador catalán desclasado. De interés particular es el reflejo que hace L. Goytisolo de las voces coloquiales y vulgarizadas de los soldados en el campamento de milicias, y que los formalistas rusos designan con el término de "skaz"23. Al final Raúl se retira de la lucha política y se refugia en la escritura. Desde el punto de vista estético, el desprendimiento del lastre ideológico de todas las doctrinas que forjaron su identidad se realiza mediante su representación paródica y satírica en la obra que está escribiendo.

En las últimas páginas de Recuento y en las tres novelas restantes: Los verdes de mayo hasta el mar (1976), La cólera de Aquiles (1979) y Teoría del conocimiento (1981), el discurso se vuelve altamente autorreferencial. El tema dominante no es tanto la des-

22 Sigo la ed. de Alfaguara, Madrid, 1983.

23 El "skaz" se orienta a la forma oral de la narración, privilegia la oralidad y las características lingüísticas como la entonación, el acento, etc. BAKHTIN señala que el "skaz" entra en la ficción como una voz socialmente diferente y trae al texto el habla vulgar y los modismos representativos de esta clase ("Discourse typology", p. 183). Aparte de Recuento se ve un ejemplo similar en el discurso de Cartucho en Tiempo de silencio. 
mitificación paródica o satírica de la realidad exterior como el desenmascaramiento de los móviles creadores y de los mecanismos que entran a formar parte de la creación literaria. En otras palabras, se pasa de una narrativa empírica a una metaficticia en la que el tema de la escritura es la escritura misma. Según M. Boyd, la novela metaficticia "focuses on the fiction making process itself: it openly examines the conventions of the realistic novel and asks the reader to do likewise" (pp. 2324). En Antagonía prima un discurso teórico y autocrítico que, cuando aparece en Recuento, el narrador lo utiliza para criticar los principios de la escuela realista precedente que enfatizaba el diálogo y el discurso mimético. Raúl ataca la novela realista que el personaje Cuadras escribe dentro de la ficción, y se marca como objetivo crear una obra que fuera:

No referencia de la realidad, sino como la realidad, objeto de posibles referencias, mundo autónomo sobre el cual, teóricamente, un lector con impulsos creadores, pudiera escribir a su vez una novela o poema (Recuento, p. 604).

Las tres novelas restantes de Antagonía se convierten en un verdadero manual de teoría literaria centrada en la función protagónica de la estructura, la lengua, el lector y el narrador en la obra literaria. En La cólera, por seleccionar una de las novelas, la narradora-protagonista, Matilde M., es la autora en la ficción del Edicto de Milán, una novelita intercalada en La cólera que narra la vida disoluta de la joven Matilde en París. Matilde es también lectora, y de la lectura de su novelita confía encontrar una solución a sus problemas sentimentales con Camila. Es, además, crítica de su obra y se enfada con la opinión del crítico inglés cuando afirma que "one can not renew the form of novels unless one drastically renews their themes" (p. 179) ${ }^{24}$. Antagonía presupone y exige la participación del lector en el proceso creador de la obra. El discurso basado en la teorización literaria es el eje sobre el que gira la narrativa de estas tres últimas novelas, pero L. Goytisolo reconoce que la escritura es una especie de negativo en el que queda reflejada la personalidad del escritor, y a través de ella el escritor mismo puede llegar al conocimiento de zonas oscuras de su personalidad. En Los verdes, el narrador observa que:

${ }^{24}$ Cito por la ed. de Alfaguara, Madrid, 1983. 
Los diversos elementos que componen la obra [son] los que configuran el verdadero rostro de su creador y, más aún, a través del lenguaje por él utilizado... que, en última instancia, puede revelarnos acerca de él cosas que ni él mismo conoce (pp. 250-251) ${ }^{25}$.

El discurso generado por la ficción es uno de los más cultivados en la ficción posmoderna española. Escritores como Juan y Luis Goytisolo, Carmen Martín Gaite, G. Torrente Ballester, Camilo J. Cela, Álvaro Cunqueiro, etc., participan activamente de este modo narrativo en el que también hace acto de presencia el discurso erótico. La sexualidad y el erotismo han despuntado en la posmodernidad; ello se debe, en parte, a una reacción lógica contra la rígida moralidad conservadora, en parte porque propicia el desarrollo discursivo de unos semas escasamente explorados hasta la fecha y, en parte, porque el texto erótico provoca en el lector un mayor acercamiento y una relación activa de reciprocidad. Comenta $\mathrm{R}$. Scholes con respecto a la relación entre sexo y ficción que los conecta:

Is the fundamental orgiastic rhythm of tumescence and detumescence, of tension and resolution, of intensification to the point of climax and consummation. In the sophisticated forms of fiction, as in the sophisticated practice of sex, much of the art consists of delaying climax within the framework of desire in order to prolong the pleasurable act itself (Fabulation, p. 26).

La episteme posmoderna no propone una sexualidad como fuerza generadora de vida y con valor mimético, sino más bien como pretexto para la creación de un discurso, como metáfora de la frustración del individuo y agostamiento de la pareja matrimonial, y como disidencia frente a lo que ha sido tabú. En Tiempo de silencio el sexo va separado de su función procreadora y unido a la muerte. Pedro quiere curar un cáncer genital, Florita es violada por su padre y muere a raíz del aborto, el padre de Dorita era un afeminado, etc. En Reivindicación, el uso de la sexualidad sirve para destruir los mitos de la castidad y pureza. En Recuento, la relación enfermiza entre la burguesía catalana y el poder central de Madrid se describe en términos sadomasoquistas, y en el resto de las novelas de

25 También por la ed. de Alfaguara, Madrid, 1983. 
Antagonía el discurso erótico refleja metafóricamente el acabamiento del amor, la rutina asfixiante y la soledad de los cónyuges. En Benet, en cambio, el discurso sobre la sexualidad ocupa un reducido espacio narrativo y cuando surge es motivado por el temor o miedo de un personaje a iniciar una nueva relación sentimental. En El mismo mar de todos los veranos (1978), de Esther Tusquets, el discurso erótico ocupa gran parte del espacio narrativo, y la (bi)sexualidad se impone como la realización efímera de un deseo y de una esperanza. El mismo mar nos lleva a considerar esta obra dentro del marco de un discurso feminista que ha generado una controvertida polémica teórica.

En un principio la crítica feminista se concentró en el estudio de la misoginia en literatura y cómo en ésta se proyectaban imágenes estereotipadas de la mujer. En una segunda fase de crítica feminista se afirman los valores temáticos y artísticos de la literatura femenina. En la década de los setenta la escritura feminista se identificó con una política lesbiana, y en los ochenta el enfoque pasa a las relaciones madre-hija ${ }^{26}$. El feminismo posmoderno arguye que un análisis feminista no puede poner de lado la dialéctica inherente en las relaciones de género. Tales relaciones, según Showalter, deben centrarse no sólo en la forma en que la mujer se muestra en las representaciones patriarcales y de poder, sino también en cómo las relaciones de género pueden ser usadas para problematizar las identidades sexuales y las diferencias entre mujeres y hombres ("Introduction...", pp. 1-3). El feminismo posmoderno trata de redefinir una retórica de la sexualidad y el poder que difiera de una visión falogocéntrica del mundo, y propone un nuevo orden que se aleje de la dominación del discurso patriarcal. D. Sherzer reconoce que escritores hombres y mujeres participan por igual del movimiento posmoderno, pero que las feministas "have shaped their own postmodernism by adding a polemical and political slant which has been laking in men's texts" (p. 168). Uno de los textos que mejor se adhiere y postula un discurso anclado en las teorías feministas es El mismo mar.

La novela tiene por tema las relaciones sexuales de la narradora-protagonista, una profesora de literatura, con su estu-

${ }^{26}$ Me sirvo de los comentarios que Elaine Showalter hace en su introducción teórica a The new feminist criticism. 
diante Clara. La protagonista se retira a un apartamento donde logra temporalmente desapegarse de sus padres, hija y esposo y entregarse a una experiencia que rompe con la educación y los principios impuestos por un orden simbólico y patriarcal. Pero el regreso final a casa supone una aceptación y sumisión al orden patriarcal. El discurso de El mismo mar recrea el poder que emana de una sociedad patriarcal y la función de la madre como partícipe y propagadora de ese dominio en la hija. Del momento en el que se produce la unión de la narradora con Clara $^{27}$ surge un discurso que nace, según E. Ordóñez, de las profundidades de su cuerpo y espíritu:

Discourse, at this juncture, thus ceases to be alienating and defined by the phallogocentric Other; the protagonist instead commences to shape her own text throughout the enunciation of her maternal corporeal desire (p. 121).

La liberación del orden patriarcal queda reducida a una aventura fortuita y fugaz que finaliza cuando Clara se va y ella regresa con su esposo Julio. El discurso matrilineal, centrado en la relación de la mujer con su madre o ascendientes femeninos y en el rechazo del discurso patriarcal, constituye también una de las coordenadas discursivas en Os habla Electra (1975) de Concha Alós, sólo que aquí Electra madre y Electra hija van asumiendo una personalidad e identidad similares.

El número de escritoras que inscriben su problemática narrativa en un discurso feminista ha crecido considerablemente a partir de la década de los ochenta. En Rupturas (1984), de Lidia Falcón, la protagonista es ya la mujer profesional e intelectual que fue educada durante el franquismo. La novela plantea las relaciones esposo-esposa, maternidad, liberación sexual, independencia económica, etc. Rosa Montero, por otro lado, trata el tema de la incomunicación entre el hombre y la mujer, así como la opresión y marginación de ésta. Algunos de sus protagonistas, no obstante, parecen más caricaturas y estereotipos que expresión de una determinada condición humana. Por ejemplo, Antonia, en Te trataré como a una reina (1983), que se libera sexualmente en avanzada edad con un

${ }^{27}$ G. Navajas comenta que la experiencia de la protagonista con Clara provoca sentimientos ambivalentes en ella y, "por una parte le permite la concretización de una antigua visión del amor siempre frustrado en el pasado. Por otra, le hace sentirse desprovista de defensas" (p. 25). 
pusilánime Damián; o la soledad de Isabel, que canta boleros en un soterrado club nocturno, son retratos femeninos poco convincentes. Más destacada, sin embargo, me parece la aportación de Montserrat Roig con su obra La hora violeta (1980), en la que Natalia y su amiga Norma mantienen discusiones teóricas sobre el feminismo y la sumisión de la mujer al hombre. Mención especial merece la obra de Carmen Martín Gaite ${ }^{28}$, profunda conocedora de la condición femenina y practicante del discurso feminista, metaficticio y fantástico en El cuarto de atrás.

El discurso fantástico conoció sus momentos de mayor auge en las pasadas décadas, pero su práctica y la atención crítica que despertó en un momento han ido en remisión. Uno de los primeros trabajos que revolucionó el estudio de lo fantástico fue el de Todorov, quien parte de un estudio estructuralista de textos mayormente escritos en el siglo xix ${ }^{29}$. Todorov no tiene en consideración la semántica ni las implicaciones socio-políticas del texto, y rechaza la teoría freudiana; pero R. Jackson asegura que muchos textos piden una lectura marxista y psicoanalítica ${ }^{30}$. Otras contribuciones teóricas al campo de lo fantástico son las de E. Rabkin, W. R. Irwin, M. Schneider, L. Vax, Ana M. Barrenechea y A. Risco.

Según Jackson, en el discurso fantástico se produce una dislocación de la lógica de este mundo que empuja a algunos de sus elementos a formar nuevas relaciones y formar algo extraño, desacostumbrado, aparentemente nuevo y diferente. Siguiendo a Bakhtin afirma que lo fantástico, a diferencia de lo maravilloso o la mimesis, mantiene una relación dialógica con lo real (pp. 8, 36). Esto nos trae de nuevo al formalismo ruso y a las teorías sobre el extrañamiento y el dialogismo, cuya influencia se ha hecho sentir en la retórica posmoderna. Otra de las cualidades relacionadas con el discurso fantástico es la

28 Para un estudio de la novela femenina consúltense, además del excelente estudio de E. Ordóñez, los trabajos de Robert Manteiga y de Janet PÉREZ.

${ }^{29}$ Una de las condiciones para que se realice lo fantástico es, según ToDorov, la vacilación que experimenta el lector, quien no sabe si se encuentra ante un hecho natural o sobrenatural. Duda compartida a veces por el protagonista. Consúltese su obra para un estudio de otras categorías.

${ }^{30} \mathrm{R}$. JACKSON indica que "psychoanalisis directs itself toward an unravelling of these laws (of human society) trying to comprehend how social structures are represented and sustained within and through us in our unconscious" (p. 6). 
de su vacuidad, de falta de conexión con la realidad, y de no ser representativa de la realidad exterior. J. P. Sartre, en un ensayo sobre Blanchot, habla del fantástico moderno como enunciados vacíos, signos sin significación, signos que no llevan a ningún lado, significantes vacíos (Sartre, pp. 60-64), y Jackson, siguiendo la línea de razonamiento de Sartre observa que "fantasy becomes a literature of separation, of discourse without an object, forshadowing that explicit focus upon problems of literature's signifying activity found in modern anti-realist texts" (p. 40). I. Bessière, por otra parte, afirma que la ficción fantástica crea otro mundo pero con las palabras, pensamientos y realidades de este mundo. Para ella el discurso fantástico produce efectos estéticos e instaura lo nuevo, y la ambigüedad calculada, lo desconocido y el erotismo le dan una forma lúdica (Bessière, pp. 11, 26-30). Bessière entiende que lo fantástico no resulta de una vacilación entre dos órdenes, como diría Todorov, sino de su contradicción (p. 57), mientras que D. Clayton sitúa esta contradicción en el plano del discurso y no en la realidad extratextual:

Fantastic discourse can be defined only by its differential relation -of conjunction and opposition - to another discourse and not to some extralinguistic reality; only language considered as a global entity has this relation, which we may well assert but cannot imagine (Clayton, p. 61).

Para Clayton, lo fantástico debe implicar la existencia de un discurso literario específico que se manifiesta a través de un repertorio de señales lingüísticas - léxicas, sintácticas, estilísticas, etc.- que lo diferencia de otras formas discursivas, y agrega que una de las propiedades que lo separa de otros modos discursivos es "its suspension of the judgment of existence" (p. 60).

Una de las obras que engrosa la larga lista de obras fantásticas es La isla de los jacintos cortados (1980) de G. Torrente Ballester. La anécdota gira en torno a un narrador que trata de enamorar a Ariadna y disuadirla de su predilección por Alain. En un lugar de Nueva Inglaterra el narrador le cuenta a su interlocutora el relato fantástico de la invención de Napoleón, en la isla de la Gorgona. El discurso fantástico nace desde un principio con el propósito de enamorar a Ariadna, por tanto el deseo y los instintos sexuales del narrador se convierten en la causa fundamental que espolea su creación fantástica. El 
narrador aprovecha la desmitificación del mito de Napoleón, uno de los temas capitales de la novela, para desvirtuar el trabajo de su rival, el historiador Alain, y atraer hacia sí a Ariadna. Con el mismo fin le comenta que Ariadna, enamorada de Teseo, fue abandonada por él tras ayudarle a salir del laberinto (p. 123) ${ }^{31}$. Al final, el narrador invalida toda su creación fantástica cuando le dice a Ariadna que el método del fuego - de donde nace la historia fantástica - es anticientífico y poético y que todo ha sido un sueño inventado. Bessière señala al respecto que la narrativa fantástica es el más artificial y deliberado modo de narración literaria, ya que se construye bajo la afirmación de la nada (p. 34). Esta inexistencia o distanciamiento con respecto a la realidad extratextual del momento se ve también en Joan Perucho y Álvaro Cunqueiro, escritores que, como Torrente Ballester, van frecuentemente al pasado para recrear unos mitos o una historia heroica que ya no existe. En el discurso de estos escritores se nota también la participación de la ironía, la fragmentación, la desmitificación, el erotismo y el autoanálisis crítico o metaficción.

Éstos son, en mi opinión, los discursos más renovadores que se apartan del discurso empírico y de los convencionalismos de la novela realista. Existen otras tendencias narrativas en la posmodernidad, como la novela policiaca, que todavía continúa proyectando una visión mimética de la realidad. M. Vázquez Montalbán señala al respecto que la mejor aportación de la novela negra a la novela española ha sido la infusión de un realismo superador "de todos los realismos viciados y agotados" (p. 9). Comenta el fracaso de la novela realista, de la experimental y lúdica y da algunas claves narrativas de los escritores de novela negra. Afirma que Mendoza no se sale de la verosimilitud literaria; que Marsé crea una tensión escritura/ lectura a fin de contar una historia; que J. Madrid escribe novela urbana posbarojiana; que A. Martín practica una mimesis de género negro norteamericano, y que él mismo practica un discurso cultural mestizo (loc. cit.). Aunque no comparto algunas de sus observaciones, sí estoy de acuerdo en que la novela negra aporta un discurso mimético basado en el diálogo y la transcripción fiel o aproximada de la realidad urbana de los bajos fondos. La novelización del pasado cercano por autores como Carlos Barral, Jorge Semprún y Juan E. Zúñiga, o del

${ }^{31}$ Cito por la ed.: La isla de los jacintos cortados, Destino, Barcelona, 1980. 
pasado lejano, como Lourdes Ortiz entre otros, continúa sirviéndose de un discurso mimético en el que la lengua nos transporta a una realidad extralingüística.

Sin menoscabar la importancia de estas últimas formas narrativas, en la novela posmoderna domina un discurso diegético e irónico en el que la lengua cuestiona su propio poder representacional y pospone indefinidamente el sentido de una obra. Los signos no se refieren a algo concreto, sino a otros signos que comentan o interpretan otros signos y así sucesivamente. Se rompe el principio de continuidad, el texto se fragmenta en unidades que no guardan continuación espaciotemporal y el lector se enfrenta a un nuevo mundo aparentemente caótico que tiene que organizar para darle sentido. El texto se hace pluralista, se abre a nuevos discursos, a nuevos estilos y experimentaciones lúdicas que subvierten el orden tradicional logocéntrico, falogocéntrico, y los mitos de la historia. $\mathrm{Si}$ antes el verbo se hacía carne al transustanciarse en realidad, ahora se convierte en discurso diegético.

Antonio Sobejano-Morán State University of New York

\section{BIBLIOGRAFÍA}

Aristoteles 1967. Poetics. Trans. G. F. Else. University of Michigan, Ann Arbor, MI.

Bakhtin, Mikhail 1978. "Dicourse typology in prose", en Readings in Russian poetics: Formalist and structuralist views. Eds. L. Matjka, \& K. Pomorska. University of Michigan, Michigan.

Bessière, Irene 1974. Le récit fantastique. La poetique de l'incertain. Libraire, Paris.

Boyd, Michael 1983. The reflexive novel. Fiction as critique. Bucknell University Press, Lewisburg, PA.

Bravo, M. Elena 1983. "Región: una crónica del discurso literario", MLN, 98, 250-258.

Clayton, David 1982. "On realistic and fantastic discourse", en Bridges to fantasy. Eds. G. E. Slusser, E. S. Rabkin, and R. Scholes. Southern Illinois University Press, Carbondale, IL.

Chatman, Seymour 1978. Story and discourse. Narrative structure in fiction and film. Cornell University Press, Ithaca, NY.

Craige, Betty T. 1979. “Tiempo de silencio: «Le grand Bouc» and the Maestro", REH, 13, 99-113. 
Deer, Glenn 1990. "The politics of modern literary innovation: A rhetorical perspective", Dalhousie Review, 70, 351-372.

Derrida, JaQues 1976. Of grammatology. Trans. G. Chakravorty Spivak. The Johns Hopkins University Press, Baltimore, MD.

- 1978. Writing and difference. Trans. A. Bass. University of Chicago Press, Chicago, IL.

Foucault, Michel 1972. "The discourse on language", The archaeology of knowledge. Pantheon Books, New York.

— 1980. The history of sexuality. T. 1. Pantheon Books, New York.

1973. The order of things: An archaeology of the human sciences. Vintage Books, New York.

Genette, Gérard 1982. Figures of literary discourse. Trans. A. Sheridan. Columbia University Press, New York.

— 1988. Narrative discourse revisted. Trans. J. E. Lewin. Cornell University Press, Ithaca, NY.

Giroux, Henry A. 1990. "Rethinking the boundaries of educational discourse: Modernism, postmodernism and feminism”, College Literature, $17,1-50$.

GrafF, GERAld 1979. Literature against itself. University of Chicago Press, Chicago, IL.

Greene, Thomas M. 1982. The light in Troy: Imitation and discovery in Renaissance poetry. Yale University Press, New Haven, CT.

HASSAN, IHAB 1987. "Making sense: The trials of postmodern discourse", New Literary History, 18, 437-459.

Herzberger, David 1975. "The emergence of Juan Benet: A new alternative for the Spanish novel", The American Hispanist, 1, 6-12.

HutcheON, Linda 1991. "Discourse, power, ideology: Humanism and postmodernism”, en Postmodernism and contemporary fiction. Ed. E. J. Smyth. B. T. Batsford, London, pp. 90-113.

JAMESON, Fredric 1972. The prision-house of language. A critical account on structuralism and Russian formalism. Princeton University Press, Princeton, NJ.

Jackson, Rosemary 1981. Fantasy and the literature of subvertion. Methuen, New York.

JefFerson, Ann 1980. The Nouveau Roman and the poetics of fiction. Cambridge University Press, Cambridge, MA.

Jenny, Laurent 1976. "La stratégie de la forme", Poétique, 27, 252-267.

Jung, Carl G. 1976. The symbolic life. Trans. R. F. C. Hull. Princeton University Press, Princeton, NJ.

Kristeva, Julia 1980. Desire in language. A semiotic approach to literature and art. Columbia University Press, New York.

— 1969. Séméotikè: Recherches pour une sémanalyse. Éds. du Seuil, Paris.

LabanyI, Jo 1989. Myth and history in the contemporary Spanish novel. Cambridge University Press, Cambridge, MA.

Manteiga, Roberto et al. (eds.) 1988. Femenine concerns in contemporary Spanish fiction by women. University of North Carolina, Chapell Hill, NC.

Мернам, John 1991. "Narratives of postmodernism", en Postmodernism and contemporary fiction. Pp. 138-155.

Navajas, Gonzalo 1987. Teoría y práctica de la novela española postmoderna. Eds. del Mall, Barcelona. 
OrdóÑEz, Elizabeth 1991. Voices of their own: Contemporary Spanish narrative by women. Bucknell University Press, Lewisburg, PA.

Orringer, Nelson R. 1984. "Epic in a paralytic state: Volverás a Región", en Critical approaches to the writings of Juan Benet. Eds. D. Herzberger, R. Manteiga, and M. A. Compitello. University Press of New England, Hanover, CT, pp. 40-50.

PÉrez, Janet 1983. Novelistas femeninas de la postguerra española. J. Porrúa Turanzas, Madrid.

Platon 1974. Republic. Trans. D. Lee. Penguin, Harmondsworth.

Pope, Randolph D. 1984. "Benet, Faulkner and Bergson's memory", en Critical approaches to the writing of Juan Benet. Pp. 111-119.

Sartre, J. Paul 1947. "«Aminadab» or the fantastic considered as a language”, Situations, 1, 56-72.

Scholes, Robert 1980. Fabulation and metafiction. University of Illinois Press, Chicago, IL.

- 1982. Semiotics and interpretation. Yale University Press, New Haven, CT.

Schraibman, José 1979. "Ruptura de «forma» y «lenguaje» en la novela española de posguerra”, Ins, núms. 396/397, 11-12.

Schwartz, Kessel 1971. "Juan Goytisolo, cultural constraints and the historical vindication of Count Julián”, H, 54, 960-966.

Sherzer, Dina 1991. "Postmodernism and feminism", en Postmodernism and contemporary fiction. Pp. 156-168.

Shklovsky, VikTor 1965. "Art as technique", en Russian formalist criticism: Four essays. Eds. L. T. Lemon, \& M. J. Reiss. University of Nebraska Press, Lincoln, NE.

Showalter, Elaine 1989. "Introduction: The rise of gender", en Speaking of gender. Ed. E. Showalter. Routledge, New York, pp. 1-13.

- (ed.) 1985. The new feminist criticism. (Essays on women literature theory). Pantheon Books, New York.

SELden, RAman 1989. A reader's guide to contemporary literary theory. The University Press of Kentucky, Lexington, KY.

Sobejano, Gonzalo 1975. Novela española de nuestro tiempo. Prensa Española, Madrid.

SPIRes, RoBert 1978. La novela española de posguerra. Creación artística y experiencia personal. Cupsa, Madrid.

Todorov, Tzvetan 1975. The fantastic: A structural approach to a literary genre. Trans. R. Howard. Cornell University Press, Ithaca, NY.

Ugarte, Michael 1981. "Tiempo de silencio and the language of displacement”, MLN, 96, 340-357.

— 1982. Trilogy of treason. An intertextual study of Juan Goytisolo. University of Missouri Press, Columbia, MO.

VÁzquez M., Manuel 1989. “Contra la novela policíaca”, Íns, núms. 512/ $513,9$.

White, Hayden V. 1987. The content of the form. Narrative discourse and historical representation. The Johns Hopkins University Press, Baltimore, MD.

— 1978. Tropics of discourse: Essays in cultural criticism. The Johns Hopkins University Press, Baltimore, MD. 